\title{
Effect of maternal undernutrition on fetal testicular steroidogenesis during the CNS androgen-responsive period in male sheep fetuses
}

\author{
M. T. Rae', S. M. Rhind ${ }^{1 *}$, P. A. Fowler ${ }^{2}$, D. W. Miller ${ }^{3}$, \\ C. E. Kyle ${ }^{1}$ and A. N. Brooks ${ }^{4}$ \\ ${ }^{1}$ Macaulay Land Use Research Institute, Craigiebuckler, Aberdeen AB15 8QH, UK; \\ ${ }^{2}$ University of Aberdeen, Department of Obstetrics and Gynaecology, Aberdeen AB25 2ZL, \\ UK; ${ }^{3}$ University of Aberdeen, Department of Agriculture and Forestry, Aberdeen AB24 5UA, \\ UK; and ${ }^{4}$ AstraZeneca, Alderly Park, Macclesfield, Cheshire SK10 4TJ, UK
}

The aim of this study was to determine the effects of maternal undernutrition, applied during physiologically relevant stages of development of the reproductive system, on reproductive development in male sheep fetuses. Groups of ewes $(n=11-19)$ were fed rations providing either $100 \%$ (high; $\mathrm{H}$ ) or $50 \%$ (low; L) of metabolizable energy requirements for live weight maintenance during selected 'windows', bounded by days $0,30,50,65$ and 110 after mating. Ewes of control groups (HH (Expts 1 and 2) and $\mathrm{HHH}$ (Expt 3)) were fed the $\mathrm{H}$ ration from mating until they were killed at day 50 (Expt 1), day 65 (Expt 2) or day 110 (Expt 3) of gestation, whereas ewes of other groups were fed the $L$ ration for the periods days $0-30$ of gestation (LH and LHH), days 31-50 or days 31-65 of gestation (HL and $\mathrm{HLH}$ ), days 65-110 of gestation (HHL), or day 0 to day 50 , day 65 or day 110 of gestation (LL and LLL) when the animals were killed. At day 50 of gestation, there was no

\section{Introduction}

There is evidence from studies of human populations that undernutrition in utero can adversely influence the physiology and health of individuals in their adult life (Barker et al., 1992; Barker, 1994). It has also been found that, in sheep, the lifetime reproductive capacity of ewes is reduced in those that are born to dams undernourished during late pregnancy or the first months of life (Gunn et al., 1995; Rhind et al., 1998). However, the underlying reasons for these effects remain unclear and it is not known whether there are comparable effects on fetuses exposed to undernutrition earlier in gestation or on the male offspring subjected to similar treatments.

In adult males of many mammalian species, nutrition has profound effects on libido and testicular function, which are thought to be mediated through alterations in

*Correspondence

Email: s.rhind@mluri.sari.ac.uk effect of nutritional treatment on mean fetal mass or fetal testicular mass, but there was increased expression of mRNA for steroidogenic acute regulatory protein (StAR) in the testes of $L L$ animals $(P<0.05)$ compared with $\mathrm{HH}$ controls. Compared with $\mathrm{HH}$ animals, the mean plasma testosterone concentrations of LL fetuses tended to be higher, but this result did not reach significance. At day 65 of gestation there were no significant differences between treatments in mean fetal masses, testicular masses, mean plasma testosterone concentrations or StAR mRNA content. At day 110 of gestation, fetal masses in the LLL group were lower $(P<0.01)$ than those of control fetuses, although no differences in testicular size or fetal plasma testosterone concentrations were recorded. It is concluded that the effects of undernutrition on reproductive development of male sheep fetuses are dependent on the timing of the period of undernutrition. gonadotrophin secretion from the pituitary gland (Martin and Walkden-Brown, 1995). The development and function of the testes in sheep fetuses are known to be critically dependent on circulating fetal gonadotrophin concentrations (Brooks et al., 1995), but the effects of undernutrition on testis development during the period of gestation before the fetal pituitary is functional is unknown.

The present study was designed to determine the effects on the development of the fetal testes of periods of maternal undernutrition, applied at physiologically relevant stages of fetal development, that is, when specific structures are forming (days 0-30) or the gonads are undergoing certain transient physiological states and the disruption of these is likely to alter subsequent function. The physiologically relevant stages of fetal development include: after sexual differentiation, early central nervous system (CNS) androgenresponsive phase (McNatty et al., 1995; day 50 of gestation); middle of the CNS androgen-responsive phase, before pituitary function (Short, 1974; Thomas et al., 1993; day 65 of gestation); and after the onset of gonadotrophin secretion (Thomas et al., 1993; day 110 of gestation). 


\section{Materials and Methods}

\section{Animal management and nutritional treatments}

All experimental procedures involving animals were conducted under the authority of the UK Home Office Animals (Scientific Procedures) Act 1986, and had local ethical committee approval.

Mature Scottish Blackface ewes were fed to achieve similar, moderately high levels of body condition before mating. All ewes were mated at a synchronized oestrus after treatment for 14 days with intravaginal progestagen pessaries (Chronolone, $30 \mathrm{mg}$; Intervet, Cambridge). At the time of mating, ewes were allocated randomly, within body condition score (BCS) class (Russel et al., 1969), to one of four (Expts 1 and 2) or five (Expt 3) groups. The ewes were fed rations designed to meet the estimated metabolizable energy (ME) requirements of pregnant ewes according to stage of pregnancy (high; H) (Robinson et al., 1983), or 50\% of that amount (low; L), and rations were adjusted according to stage of pregnancy and treatment group.

The diet comprised pelleted feed (Green Keil, North Eastern Farmers Ltd) and hay, and provided an estimated 8.0 and 4.0 MJ ME day ${ }^{-1}$ to $\mathrm{H}$ and $\mathrm{L}$ animals, respectively, for the duration of Expts 1 and 2, and the first 80 days of Expt 3 (see below). From the time of mating onwards, sheep were housed individually under conditions of natural daylength with access to water ad libitum.

In Expt 3, the fetal burdens of all ewes were determined by ultrasound scanning at day 80 of gestation and rations were then increased to maintain the same difference in nutritional state between treatments (Robinson et al., 1983). All ewes were weighed and body condition scores determined every 21 days throughout the experiment.

\section{Experiment 1: testis development at day 50 of gestation}

Ewes ( $n=15$ per group) with a mean live weight ( \pm SEM) of $59.0 \pm 0.62 \mathrm{~kg}$ and a mean BCS of $2.5 \pm 0.02$ at mating were housed and fed in individual pens as follows: $\mathrm{HH}$ : $100 \%$ live weight maintenance ration $(M)$ from mating to day 50 of gestation; $\mathrm{LH}: 50 \% \mathrm{M}$ from mating to day 30 of gestation and $100 \% \mathrm{M}$ from day 31 to day 50 of gestation; HL: $100 \% \mathrm{M}$ from mating to day 30 of gestation and $50 \% \mathrm{M}$ from day 31 to day 50 of gestation; LL: $50 \% \mathrm{M}$ from mating to day 50 day of gestation.

\section{Experiment 2: testis development at day 65 of gestation}

Ewes ( $n=12$ per group) with a mean live weight of $58.7 \pm 0.82 \mathrm{~kg}$ and a BCS of $2.4 \pm 0.03$ at mating were housed and fed in individual pens according to the same regimen as in Expt 1 except that ewes were killed at day 65 instead of day 50 of gestation and the second treatment window of each group was extended accordingly.

\section{Experiment 3: testis development at day 110 of gestation}

Ewes ( $n=11-19$ per group) with a mean live weight of $59.3 \pm 0.74 \mathrm{~kg}$ and a mean BCS of $2.5 \pm 0.02$ at mating were housed and treated according to the regimens described for Expt 2 except that animals were killed at day 110 of gestation and a third period of undernutrition was applied between day 66 and day 110 of gestation.

\section{Tissue collection and processing (Experiments 1, 2 and 3)}

Fetuses and ewes bearing twin or single fetuses in Expts 1, 2 and 3 were killed by administration of a barbiturate overdose to the ewe (Euthatal; $500 \mathrm{mg} \mathrm{ml}^{-1}, 30 \mathrm{ml}$, i.v.; Rhone Merieux, Harlow) on day 50, day 65 or day 110 of pregnancy, respectively. Male fetuses were recovered and weighed. Fetal blood was sampled by cardiac puncture. Fetal testes were removed and weighed. One testis of each pair was immersion-fixed in Bouin's solution for $5.5 \mathrm{~h}$. Testes fixed in Bouin's were rinsed in 70\% ethanol and transferred to $70 \%$ ethanol before they were dehydrated and embedded in paraffin wax using standard techniques. The other testis was embedded in OCT cutting compound by freezing in isopentane over dry ice and was stored at $-70^{\circ} \mathrm{C}$ until analysis. In all three experiments, discrepancies between the numbers of ewes in each group and the numbers of fetuses were attributable to the fact that this part of the study concerned only male fetuses.

\section{Immunohistochemistry and in situ hybridization}

Sections $(5 \mu \mathrm{m})$ were cut from paraffin wax-embedded testes and mounted on slides coated with poly-L-lysine (Sigma, Poole). Sections (four per testis) were cut and stained immunohistochemically for P450 C17-ahydroxylase, 17,20lyase (P450C17) to identify types of steroidogenic cell, using the method of Murray et al. (2000) and antiserum kindly donated by Professor Ian Mason (University of Edinburgh). The antiserum has been validated for use on sheep samples (France et al., 1988; Rainey et al., 1991).

Testes frozen in OCT compound were sectioned to $7.5 \mu \mathrm{m}$ (triplicate sections for each testis) and mounted on sterile RNAase-free poly-L-lysine-coated glass slides before immersion fixation in $4 \%(w / v)$ paraformaldehyde. Sections were then analysed by in situ hybridization according to the method of Sirinathsinghji et al. (1990), using oligonucleotide cDNA probes labelled with ${ }^{35} \mathrm{~S}$ at the $3^{\prime}$ end using terminal deoxynucleotidyl transferase (Boehringer Mannheim, Mannheim). The probes used were specific to StAR and P450C17 to show the expression of key parts of the steroidogenic pathway. 45-mer oligonucleotide cDNA probes were synthesized by Gibco BRL Life Technologies Ltd (Paisley) using sequences obtained from the SwissPROT database. At the time of the study only a partial sequence of the ovine P450C17 gene was available and so probes were constructed from human P450C17 bases 146-190 (Chung et al., 1987), which showed high crossspecies homology, and ovine StAR bases 514-558 (Juengel et al., 1995). In all cases, each in situ hybridization involved hybridization with 150000 c.p.m. of the labelled probe, and each experimental run included sense-probe negative controls, negative controls in which a 100-fold excess of 
unlabelled anti-sense probe was included to assess any non-specific binding of anti-sense oligonucleotide, and a positive control (adult sheep testis). In addition, all samples from each experiment were processed in the same batch to allow comparison between treatment groups within experiment. After post-hybridization washes were complete, slides were dehydrated and placed against autoradiography film (Kodak X-omat), with a ${ }^{14} \mathrm{C}$ internal standard strip (1.11-32.41 kBq g-1 microscales) (Amersham Biosciences, Little Chalfont). After a suitable exposure time, plates were developed by standard techniques and scanned using a densitometry computer package (Image Pro-Plus), and semi-quantitative data concerning the amount of ${ }^{35} \mathrm{~S}$ hybridized to each individual section were generated using a standard curve constructed from the ${ }^{14} \mathrm{C}$ standard. Slides were then dipped in Kodak NTB-2 photographic emulsion, incubated at $4^{\circ} \mathrm{C}$ for 6 weeks, and developed according to the manufacturer's protocols.

\section{Immunoassay of plasma samples}

Testosterone concentrations were determined using a kit (Delfia Testosterone; Perkin-Elmer, Wallac Oy, Turku). The detection limit was $0.4 \mathrm{nmol} \mathrm{I}^{-1}$ and intra- and interassay coefficients of variation were 7.7 and $9.7 \%$, respectively.

\section{Statistical analyses}

The effects of treatment and litter size on mean fetal mass, fetal testis mass, testosterone concentration and hybridization signal were analysed separately for each experiment using two-way ANOVA, in which the main effects were treatment and litter size, using specific contrasts between controls and treated groups. Testosterone data were transformed logarithmically before analysis as they showed a skewed distribution. In the case of testosterone concentration, treatment groups were compared with control values both separately and in combination, that is, control versus all groups subjected to a period of undernutrition.

\section{Results}

Experiment 1: testis development and function at day 50 of gestation

In the animals killed at day 50 of gestation, the respective mean ( \pm SEM) live weights and body condition scores of ewes in each treatment group were $53.9 \pm 1.36 \mathrm{~kg}$ and $2.5 \pm 0.06(\mathrm{HH}), 52.7 \pm 1.04 \mathrm{~kg}$ and $2.3 \pm 0.05(\mathrm{LH})$, $50.0 \pm 1.10 \mathrm{~kg}$ and $2.3 \pm 0.06(\mathrm{HL})$ and $50.1 \pm 1.12 \mathrm{~kg}$ and $2.3 \pm 0.06(\mathrm{LL})$.

There were no significant differences among nutritional treatments in either fetal mass or testis mass (Table 1). However, mean fetal plasma testosterone concentrations were significantly higher in fetuses derived from feed-restricted groups (restricted groups combined versus control; $P<0.05$ ) than in $\mathrm{HH}$ control fetuses (Table 1). Owing to the high variability in steroid concentrations, the mean concentrations of all the individual treatment groups were not significantly different from that of the control group; however, there was a strong trend towards higher mean testosterone concentrations in $\mathrm{LL}$ than in $\mathrm{HH}$ fetuses, although this result did not reach significance.

Immunohistochemical staining for P450C17 showed that the fetal testis was steroidogenically active and showed advanced development of seminiferous tubules and interstitial areas (Fig. 1a). There were no significant differences with treatment in the expression of mRNA for P450C17, as detected by in situ hybridization, but there was a marked trend towards increased expression in fetuses from ewes that were undernourished from day 0 to day 50 of gestation ( $\mathrm{HH}$ versus $\mathrm{LL}$ ) (result not shown).

Expression of StAR mRNA was significantly higher in the testes of $\mathrm{LL}$ fetuses than in those of $\mathrm{HH}$ fetuses $(P<0.05)$ (Figs 2 and 3). Expression in $\mathrm{HL}$ and $\mathrm{LH}$ animals was intermediate between that of $\mathrm{HH}$ and $\mathrm{LL}$ animals, but did not differ significantly from either the $\mathrm{HH}$ or $\mathrm{LL}$ groups.

There were no differences with litter size in any of the variables measured.

\section{Experiment 2: testis development and function at day 65 of gestation}

In the animals killed at day 65 of gestation, the respective mean ( \pm SEM) live weights and body condition scores in each treatment group were $54.5 \pm 1.96 \mathrm{~kg}$ and $2.5 \pm 0.06$ $(\mathrm{HH}), 54.2 \pm 1.05 \mathrm{~kg}$ and $2.4 \pm 0.04(\mathrm{LH}), 51.8 \pm 1.94 \mathrm{~kg}$ and $2.4 \pm 0.06(\mathrm{HL})$ and $49.9 \pm 1.07 \mathrm{~kg}$ and $2.3 \pm 0.03$ (LL).

There were no significant differences between fetuses of any of the restricted-nutrition treatments and control fetuses with respect to fetal mass, fetal testis mass (Table 1), mean fetal plasma testosterone concentration (Table 1), or expression of mRNA for P450C17 or StAR. Immunohistochemistry for $\mathrm{P} 450 \mathrm{C} 17$ revealed that there was further development of the structural organization of the testes compared with that at day 50 of gestation (Fig. 1c).

There were no differences with litter size in any of the variables measured.

\section{Experiment 3: testis development and function at day 110 of gestation}

At the time the animals were killed, the respective mean ( \pm SEM) live weights and body condition scores in each treatment group were $62.4 \pm 1.99 \mathrm{~kg}$ and $2.4 \pm 0.04(\mathrm{HHH})$, $62.3 \pm 1.66 \mathrm{~kg}$ and $2.4 \pm 0.03(\mathrm{LHH}), 61.6 \pm 1.85 \mathrm{~kg}$ and $2.3 \pm 0.06(\mathrm{HLH}), 55.6 \pm 1.46 \mathrm{~kg}$ and $2.2 \pm 0.04(\mathrm{HHL})$, and $48.7 \pm 1.34 \mathrm{~kg}$ and $1.9 \pm 0.05(\mathrm{LLL})$.

Maternal undernutrition from day 0 to day 110 of gestation (LLL) was associated with a significant reduction in mean fetal mass $(P<0.01)$ but none of the individual periods of undernutrition significantly affected mean fetal testis mass (Table 1). There were no significant differences between treatment groups in mean plasma testosterone 
Table 1. Effects of maternal undernutrition on mean ( \pm SEM) fetal masses, fetal testis masses and fetal plasma testosterone concentrations in male sheep fetuses

\begin{tabular}{lcrrr}
\hline Experiment 1 (day 50 of gestation) & HH & LH & HL & LL \\
\hline$n$ & 5 & 10 & 7 & 5 \\
Fetal mass (g) & $28.1 \pm 2.45$ & $25.8 \pm 0.77$ & $25.4 \pm 1.96$ & $27.2 \pm 2.34$ (NS) \\
Testes mass (mg) & $11.3 \pm 1.00$ & $13.4 \pm 0.52$ & $11.8 \pm 0.75$ & $12.4 \pm 1.24(\mathrm{NS})$ \\
Testosterone (nmol I-1) & $0.6 \pm 0.36$ & $6.7 \pm 2.52$ & $3.5 \pm 1.64$ & $5.57 \pm 2.33^{\mathrm{a}}$ \\
\hline Experiment 2 (day 65 of gestation) & $\mathrm{HH}$ & $\mathrm{LH}$ & $\mathrm{HL}$ & \\
\hline$n$ & 4 & 9 & 6 & $\mathrm{LL}$ \\
Fetal mass (g) & $111.7 \pm 17.95$ & $115.0 \pm 5.28$ & $108.2 \pm 5.19$ & $99.2 \pm 6.22(\mathrm{NS})$ \\
Testes mass (mg) & $29.6 \pm 3.54$ & $30.2 \pm 1.04$ & $29.1 \pm 1.91$ & $28.2 \pm 2.00(\mathrm{NS})$ \\
Testosterone (nmol I-1) & $1.5 \pm 1.03$ & $2.4 \pm 1.18$ & $1.6 \pm 1.00$ & $1.3 \pm 0.45$ (NS) \\
\hline
\end{tabular}

Experiment 3

\begin{tabular}{lccccc} 
(day 110 of gestation) & HHH & LHH & HLH & HHL & LLL \\
\hline$n$ & 9 & 12 & 10 & 13 & 14 \\
Fetal mass $(\mathrm{kg})$ & $2.2 \pm 0.11$ & $2.3 \pm 0.06$ & $2.2 \pm 0.06$ & $2.0 \pm 0.05$ & $1.9 \pm 0.05^{* *}$ \\
Testes mass $(\mathrm{mg})$ & $475.6 \pm 40.32$ & $466.4 \pm 34.75$ & $466.1 \pm 22.20$ & $423.9 \pm 16.67$ & $447.6 \pm 22.54(\mathrm{NS})$ \\
Testosterone $(\mathrm{nmol} \mathrm{I-1)}$ & $3.7 \pm 2.55$ & $2.1 \pm 0.50$ & $3.0 \pm 0.91$ & $2.5 \pm 0.71$ & $3.0 \pm 1.41(\mathrm{NS})$ \\
\hline
\end{tabular}

Significance values pertain to the comparisons of each undernourished group relative to the control $(\mathrm{HH})$.

Testicular mass data are the means of treatment groups, derived from the mean mass of the testes from each fetus.

At day 50 of gestation, mean testosterone concentration was lower $(P<0.05)$ in $\mathrm{HH}$ fetuses than in the combined undernourished groups ( $\mathrm{LL}$, $\mathrm{LH}$ and $\mathrm{HL}$ ) and there was a strong trend towards higher testosterone concentrations in LL compared with $\mathrm{HH}$ fetuses, although the result did not reach significance $(\mathrm{a} P=0.08)$.

$\mathrm{H}: 100 \%$ of metabolizable energy requirements for live weight maintenance; L: $50 \%$ of metabolizable energy requirements for live weight maintenance; NS: not significant.

$* * P<0.01$.

concentrations (Table 1). Immunohistochemical staining for P450C17 indicated that the testes were likely still to be steroidogenically active, and it was observed that further development and differentiation of the seminiferous tubules had occurred (Fig. 1e).

Owing to low expression of mRNA for both StAR and P450C17 at day 110 of gestation, the in situ hybridization quantification method used was not sufficiently sensitive to reveal any differences in mRNA expression attributable to nutritional treatments.

There were no differences with litter size in any of the variables measured.

\section{Discussion}

Measurements of specific mRNA contents indicated that the physiology of the developing testes in sheep fetuses was significantly altered by nutrient restriction. Undernutrition during the first 50 days of fetal development was clearly associated with increased expression of the key steroidogenically rate-limiting cholesterol transporter StAR. Owing to the large intragroup variability, it was not possible to demonstrate conclusively that nutrient restriction for a part (0-30 days or 31-50 days) of the period had a smaller effect, but the patterns of expression were not inconsistent with this contention. The trend towards increased expression of P450C17, although not significant, indicated that the enzyme systems required for steroid formation also may have been upregulated in fetuses from undernourished mothers. This is the first study in which the patterns of steroidogenic enzyme expression and fetal testosterone concentrations have been investigated jointly at these early stages of development.

Testosterone concentrations at day 50 of gestation in the respective treatment groups were consistent with the patterns of steroidogenic enzyme mRNA expression. Concentrations were generally higher in fetuses from dams that had been subjected to a period of undernutrition, but the difference in mean concentrations was not significant as a result of the large inter-animal variation. This finding may reflect small differences in the age of the fetuses and associated stages of development and steroidogenic capacity. These differences may, in turn, reflect differences in the supply of relevant substrates, together with differences between individuals in the expression of enzyme activity.

As these treatment effects were expressed before the onset of gonadotrophin secretion from the fetal pituitary, it is clear that the changes in steroidogenic capacity were not 

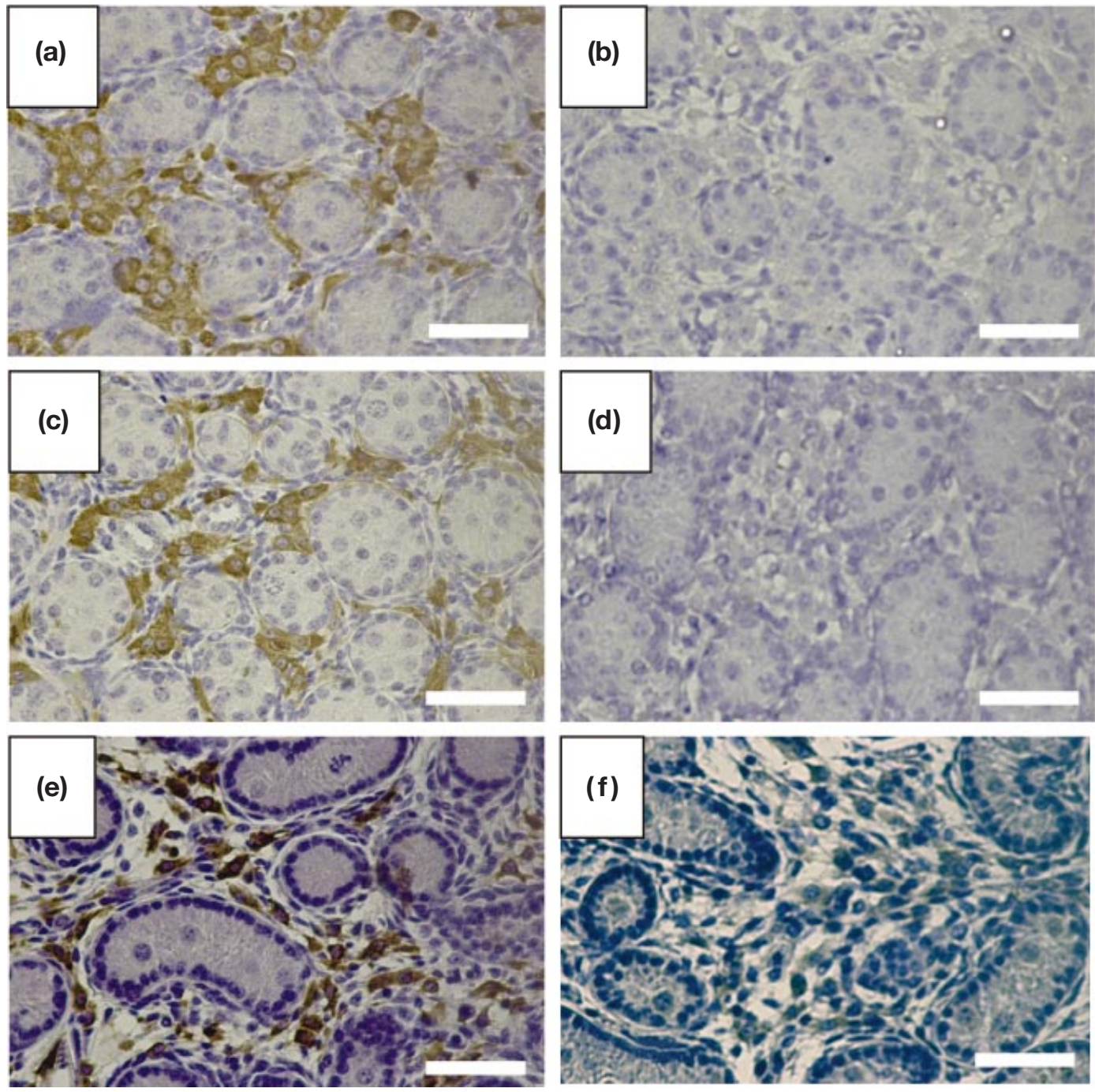

Fig. 1. Testes from male sheep fetuses at (a) day 50, (c) day 65 and (e) day 110 of gestation stained immunohistochemically for P450C17 2 hydroxylase,17,20 lyase. Staining indicates that testes remain steroidogenically active. $(b, d, f)$ Negative control slides for testes from sheep fetuses at days 50, 65 and 110 of gestation, respectively, for which primary antiserum was substituted for an identical concentration of non-immune IgG. All tissues were from $\mathrm{HH}$ control groups (ewes fed 100\% of metabolizable energy requirements for live weight maintenance from mating until the animals were killed), although similar results were observed in all groups irrespective of nutritional treatment. Scale bars represent $40 \mu \mathrm{m}$.

attributable to altered hypothalamo-pituitary function. The mechanisms that control fetal testicular steroidogenesis before fetal pituitary function are unknown. However, it is possibile that altered testosterone production may affect central control mechanisms such as the hypothalamopituitary axis in the developing fetus, as altered production occurs during the period when the CNS is at its most sensitive to androgen concentrations (Short, 1974).

The absence of a difference in mean testosterone concentrations at day 65 and day 110 of gestation indicates that this response to maternal undernutrition was expressed only during a relatively short period of gestation and that this critical window apparently ended before day 65 .
Owing to the high variation in testosterone concentrations between fetuses, the observed treatment difference in this variable at day 50 should be viewed with caution. However, these data, in conjunction with the measurements of StAR mRNA expression, imply that undernutrition upregulated fetal testicular steroidogenesis at day 50 of gestation through mechanisms that remain to be determined.

The apparent increase in testosterone secretion at day 50 coincides with a period of enhanced CNS sensitivity to androgens, which, in sheep, occurs between day 30 and day 90 of gestation (Short, 1974). Studies of pregnant rats subjected to environmental stress have demonstrated an advancement of the surge in fetal plasma testosterone 


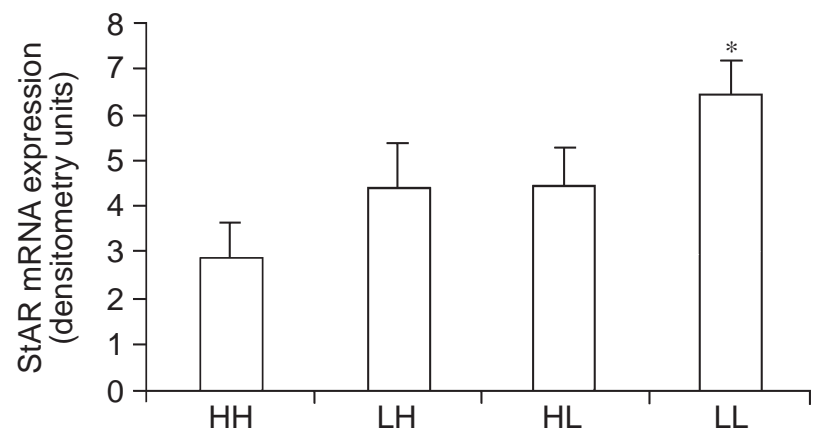

Fig. 2. Effect of maternal nutrition on steroidogenic acute regulatory protein (StAR) expression in testes of male sheep fetuses at day 50 of gestation. Underfeeding of pregnant ewes from day 0 to day 50 of gestation (LL; Expt 1) resulted in a significant increase in the amount of mRNA for StAR $(* P<0.05)$ compared with that in control fetuses $(\mathrm{HH}) . \mathrm{HH}: 100 \%$ live weight maintenance ration (M) from mating to day 50 of gestation; LL: $50 \% \mathrm{M}$ from mating to day 50 day of gestation.

concentrations by approximately 1 day at a stage of pregnancy broadly equivalent to day 50 of gestation in sheep. It has been postulated that this advancement is associated with abnormal adult sexual behaviour (Ward and Weisz, 1980). Other studies into the role of androgens in the development of reproductive centres in the CNS of sheep fetuses (Wood et al., 1991, 1995; Kosut et al., 1997; Kim et al., 1999; Masek et al., 1999) have shown that females, males and androgenized females have similar numbers of hypothalamic GnRH neurones, but that fewer synaptic inputs to these neurones are found in males and androgenized females compared with normal females, indicating that testosterone has a role in the organization of inputs to the neurones. The greater number of synaptic inputs on female GnRH neurones is thought to form the basis for the oestradiol-stimulated surges of $\mathrm{GnRH}$ that occur in females but not in males (Kim et al., 1999). In addition, it is thought that within the gestational window of day 30-90 in sheep, other aspects of reproductive function can be influenced by androgens. For example testosterone exposure during day $30-51$ or day $65-86$ of gestation can advance the timing of neuroendocrine maturity in a dosedependent manner (Kosut et al., 1997), without altering the mechanism responsible for the $\mathrm{LH}$ surge in females (Wood et al., 1995). Collectively, these data indicate the importance of fetal testosterone in the development of CNS function. However, whether the high testosterone concentrations observed in male fetuses have any effects in adult life remains to be determined.

At day 110 of gestation (Expt 3), it is likely that the significant reduction in the mean mass of fetuses born to ewes underfed continuously from conception (LLL) was attributable to the inability of the ewe to meet the nutrient requirements for the large increase in the rate of fetal growth that occurs at about this time (Robinson et al., 1983). However, the absence of any treatment differences in terms of
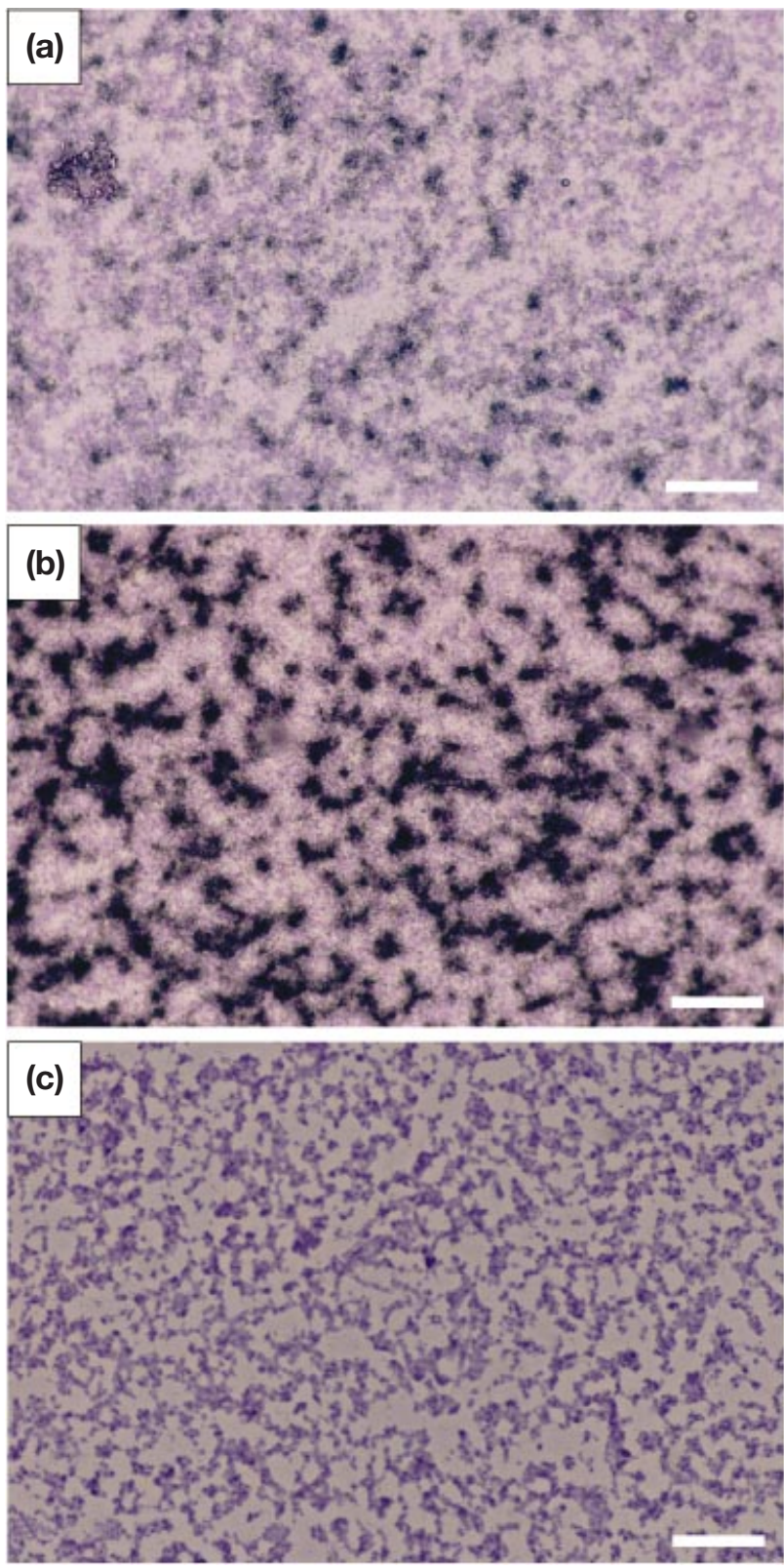

Fig. 3. Steroidogenic acute regulatory protein (StAR) mRNA in situ hybridization in testes of male sheep fetuses (Expt 1). (a) Fetal testis at day 50 of gestation from a control pregnancy $(\mathrm{HH})$. Hybridization signal can be observed in single Leydig cells. (b) Fetal testis at day 50 of gestation from a ewe with a restricted nutritional intake from day 0 to day 50 of gestation (LL). Note the stronger hybridization signal compared with that in (a). (c) Sense control hybridization to fetal testes at day 50 of gestation. All panels are representative sections from the same in situ hybridization experiment. $\mathrm{HH}: 100 \%$ live weight maintenance ration $(\mathrm{M})$ from mating to day 50 of gestation; LL: $50 \% \mathrm{M}$ from mating to day 50 of gestation. Scale bars represent $100 \mu \mathrm{m}$.

mean testicular masses, whether expressed in absolute terms or as a percentage of total body weight, implies that the gross physical development of the gonads was not visibly affected by undernutrition up to this time. 
The low expression of StAR and P450C17 mRNA at day 110 of gestation, compared with expression at days 50 and 65 , in conjunction with testosterone concentrations similar to those recorded at the earlier stages, appears anomalous. These results may be explained by the fact that testosterone secretion decreases rapidly at about this time (Pomerantz and Nalbandov, 1975) and so expression of the proteins responsible for synthesis of testosterone would also be expected to decrease in anticipation of the decrease in testosterone. In addition, there may be changes in factors other than the two steroidogenic components measured here, such as steroid-metabolizing enzymes or transporter systems. Furthermore, the fetal testis is under the influence of the pituitary by the late stages of gestation and is therefore exposed to different hormonal regulation.

In conclusion, this is the first study to demonstrate that, although maternal undernutrition has no observable effects on the gross anatomy of fetal testes, it can induce increased fetal steroidogenic capacity during a specific period of early pregnancy. Furthermore, there is some evidence of an associated increase in testosterone secretion. Whether these effects have any long-term consequences on male fertility and sexual behaviour remains to be determined.

The authors wish to acknowledge the excellent animal husbandry of the staff of Glensaugh Research Station. They also wish to acknowledge the contributions of Biomathematics and Statistics, Scotland to the design of statistical analyses. The authors thank J. I. Mason for the kind gift of P450C17 antiserum, and Tom Aldridge (AstraZeneca CTL) for advice on in situ hybridization methods and probe design. They are also grateful to P. Cunningham for performing the testosterone assays.

\section{References}

Barker DJP (1994) Mothers, Babies and Diseases in Later Life British Medical Journal Publishing Group, London

Barker DJP, Bull AR, Osmond C and Simmonds SJ (1992) Fetal and placental size and risk of hypertension in adult life. In Fetal and Infant Origins of Adult Disease pp 175-194 Ed. DJP Barker. British Medical Journal Publishing Group, London

Brooks AN, McNeilly AS and Thomas GB (1995) Role of GnRH in the ontogeny and regulation of the fetal hypothalamo-pituitary-gonadal axis in sheep Journal of Reproduction and Fertility Supplement $\mathbf{4 9}$ 163-175

Chung BC, Picado-Leonard J, Haniu M, Bienkowski M, Hall PF, Shively JE and Miller WL (1987) Cytochrome p450c17 (steroid 17 alphahydroxylase/17,20 lyase): cloning of human adrenal and testis cDNAs indicates the same gene is expressed in both tissues Proceedings National Academy of Sciences USA 84 407-411

France JT, Magness RR, Murry BA, Rosenfeld CR and Mason JI (1988) The regulation of ovine placental steroid $17 \alpha$-hydroxylase and aromatase by glucocorticoid Molecular Endocrinology 2 193-199

Gunn RG, Sim D and Hunter EA (1995) Effects of nutrition in utero and in early life on the subsequent lifetime reproductive performance of
Scottish Blackface ewes in two management systems Animal Science $\mathbf{6 0}$ 223-230

Juengel JL, Meberg BM, Turzillo AM, Nett TM and Niswender GD (1995) Hormonal regulation of messenger ribonucleic acid encoding steroidogenic acute regulatory protein in ovine corpora lutea Endocrinology 136 5423-5429

Kim SJ, Foster DL and Wood RI (1999) Prenatal testosterone masculinizes synaptic input to gonadotropin-releasing hormone neurons in sheep Biology of Reproduction 61 599-605

Kosut SS, Wood RI, Herbosa-Encarnacion C and Foster DL (1997) Prenatal androgens time neuroendocrine puberty in the sheep: effect of testosterone dose Endocrinology 138 1072-1077

McNatty KP, Smith P, Hudson N, Heath D, Tisdall DOW and Brawtal $\mathbf{R}$ (1995) Development of the sheep ovary during fetal and early neonatal life and the effect of fecundity genes Journal of Reproduction and Fertility Supplement 49 123-135

Martin GB and Walkden-Brown SW (1995) Nutritional influences on reproduction in mature male sheep and goats Journal of Reproduction and Fertility Supplement 49 437-449

Masek KS, Wood RI and Foster DL (1999) Prenatal dihydrotestosterone differentially masculinizes tonic and surge modes of luteinizing hormone secretion in sheep Endocrinology 140 3459-3466

Murray TJ, Fowler PA, Abramovich DR, Haites N and Lea RG (2000) Markers of development and endocrine function in the human fetal testis Journal of Clinical Endocrinology and Metabolism $854812-4817$

Pomerantz DK and Nalbandov AV (1975) Androgen level in the sheep fetus during gestation Proceedings of the Society for Experimental Biology and Medicine 149 413-416

Rainey WE, Oka K, Magness RR and Mason JI (1991) Ovine fetal adrenal synthesis of cortisol: regulation by ACTH, angiotensin II and transforming growth factor beta Endocrinology 129 1784-1790

Rhind SM, Elston DA, Jones JR, Rees ME, McMillen SR and Gunn RG (1998) Effects of restriction of growth and development of Brecon Cheviot ewe lambs on subsequent lifetime reproductive performance Small Ruminant Research $30121-126$

Robinson JJ, Russel AJF, Treacher TT and Kilkenny JB (1983) Feeding the ewe Meat and Livestock Commision Sheep Improvement Services

Russel AJF, Doney JM and Gunn RG (1969) Subjective assessment of body fat in live sheep Journal of Agricultural Science, Cambridge 72 451-454

Short RV (1974) Sexual differentiation of the brain of sheep INSERM 32 $121-142$

Sirinathsinghji DJS, Morris BJ, Wisden W, Northrop A, Hunt SP and Dunnett SB (1990) Gene expression in striatial grafts - I. Cellular localization of neurotransmitter mRNAs Neuroscience 34 675-686

Thomas GB, McNeilly AS and Brooks AN (1993) Development of gonadotrophs and thyrotrophs in the female foetal sheep pituitary: immunocytochemical localization studies Journal of Neuroendocrinology 5 157-161

Ward IL and Weisz J (1980) Maternal stress alters plasma testosterone in fetal males Science 207 328-329

Wood RI, Ebling FJP, I'anson H, Bucholtz DC, Yellon SM and Foster DL (1991) Prenatal androgens time neuroendocrine sexual maturation Endocrinology 128 2457-2486

Wood R, Mehta V, Herbosa CG and Foster DL (1995) Prenatal testosterone differentially masculinizes tonic and surge modes of luteinizing hormone secretion in the developing sheep Neuroendocrinology 62 238-247

Received 4 December 2001.

First decision 6 February 2002.

Accepted 26 February 2002. 